\title{
Prevalence of class 1 and 2 integrons among the multidrug resistant uropathogenic strains of Escherichia coli
}

\author{
Haddadi Azamª Somayeh Mikaili Ghezeljeha, Shavandi Mahmoud ${ }^{\mathrm{b}}$ \\ ${ }^{a}$ Department of Biology, Karaj Branch, Islamic Azad University, Karaj 31331-485, Iran \\ ${ }^{b}$ Microbiology and Biotechnology Group, Research Institute of Petroleum Industry, Tehran 14665- \\ 137, Iran
}

\begin{abstract}
Background: Multidrug resistance is a serious problem in the treatment of urinary tract infections. Horizontal gene transfer, directed by strong selective pressure of antibiotics, has resulted in the widespread distribution of multiple antibiotic resistance genes. The dissemination of resistance genes is enhanced when they are trapped in integrons.

Objectives: To determine the prevalence of integrons among multidrug resistant Escherichia coli strains collected from regional hospitals and private clinical laboratories in Alborz province.

Methods: The susceptibility of 111 clinical Escherichia coli isolates was tested using a Kirby-Bauer disk diffusion method for common antibiotics. Isolates were screened for the production of extended spectrum $\beta$-lactamases (ESBLs) using a double disk synergy test. The existence of integrons was confirmed by amplification of the integrase gene and their class determined via analysis of PCR products by PCR-RFLP.

Results: Isolates showed the highest resistance to amoxicillin. Nitrofurantoin, amikacin, and ceftizoxime were the most effective antibiotics in vitro. Eighty-eight isolates of 111 (79\%) were resistant to more than three unrelated drugs. We found 30\% of the multidrug resistant isolates harbor integrons. Class 1 and 2 integrons were detected in 25 and 1 isolates, respectively. ESBL screening of strains showed 45 isolates (40\%) were positive; $22 \%$ of the ESBL-positive isolates carried class 1 integrons and the frequency of MDR in ESBLpositive isolates was $93 \%$.

Conclusion: The existence of integrons in only $29.5 \%$ of multidrug resistant isolates showed that besides integrons, antibiotic resistance genes were probably carried on other transferable elements lacking integrons, such as transposons or plasmids.
\end{abstract}

Keywords: ESBL, Escherichia coli, integron, multidrug resistance, PCR-RFLP

In recent years, because of excessive and unregulated use of antibiotics, the threat of acquisition of antibiotic resistance by pathogens is growing [1]. Misuse and overuse of antibiotics have played a substantial role in the development of multidrug resistant (MDR) bacteria. Multidrug resistance is a serious problem in therapy of patients with urinary tract infections. Horizontal transfer of antibiotic resistance genes has led to the rapid emergence of antibiotic resistance among clinical isolates of bacteria [2] and resulted in the widespread distribution of multiple antibiotic resistance genes on plasmids and

Correspondence to: Haddadi Azam, Department of Biology, Karaj Branch, Islamic Azad University, Karaj 31331-485, Iran. E-mail:haddadia@kiau.ac.ir transposons among many gram-negative isolates. The dissemination of resistance genes is greatly enhanced when they are trapped in a mobile gene cassette, the so-called integron [3]. Integrons are conserved DNA sequences that provide an efficient means for capturing and spreading of antimicrobial resistance genes [4] and are carried on episomal genetics structures. The essential components of an integron include the integrase gene (intI), the attachment site $(a t t I)$, and the promoter $\left(P_{a n t}\right)$, which promotes the expression of any suitably integrated gene(s). Integrase is a member of the tyrosine site-specific recombinase family that catalyzes the excision and integration of DNA units by performing two consecutive strand breakages and rejoining steps [5]. Four classes of integrons so far identified are 
distinguished by their respective integrase (int) genes. Most of the resistance integrons found in clinical isolates of Enterobacteriaceae are class 1 integrons, which are highly associated with resistance to antimicrobial agents [6]. Integrons are of clinical importance, because the use of only one antibiotic may activate the expression of a whole gene cassette.

Because there is not much published data available on the detection of integrons in MDR isolates of uropathogenic Escherichia coli from Iranian medical centers, the aim of this study was to survey the prevalence of MDR and the frequency of class 1 and 2 integrons by restriction fragment length polymorphism analysis of PCR products (PCR-RFLP) of clinical isolates of $E$. coli in the immigration friendly city of Karaj, Iran and to investigate associations between MDR and existence of integrons.

\section{Materials and methods Bacterial strains}

Between April and July 2013, 111 anonymized nonduplicate $E$. coli isolates from urine samples were collected from 4 hospitals and 2 private clinical laboratories of Alborz province, Karaj city. Isolates were identified as E. coli based on standard biochemical tests [7].

\section{Antimicrobial susceptibility assay}

The susceptibilities of all isolates to 19 different antibiotics were determined using a Kirby-Bauer disk diffusion method, as suggested by the Clinical and Laboratory Standards Institute [8]. The zone of inhibition of each isolate was tested on Muller-Hinton agar medium with commercial antimicrobial disks (Padtan Teb Co, Tehran, Iran). The antibiotic disks used in this study were gentamicin $(10 \mu \mathrm{g})$, amikacin (30 $\mu \mathrm{g})$, amoxicillin $(10 \mu \mathrm{g})$, ceftazidime (30 $\mu \mathrm{g})$, cephalothin (30 $\mu \mathrm{g}$ ), cephalexin (30 $\mu \mathrm{g}$ ), ceftizoxime (30 $\mu \mathrm{g})$, ceftriaxone $(30 \mu \mathrm{g})$, imipenem $(10 \mu \mathrm{g})$, nalidixic acid (30 $\mu$ g), ciprofloxacin (5 $\mu \mathrm{g})$, norfloxacin $(10 \mu \mathrm{g})$, co-trimoxazole $(25 \mu \mathrm{g})$, tetracycline $(30 \mu \mathrm{g})$, chloramphenicol (30 $\mu \mathrm{g})$, ofloxacin (5 $\mu \mathrm{g})$, levofloxacin (5 $\mu \mathrm{g})$, amoxicillin/clavulanic acid (20/10 $\mu \mathrm{g})$, and nitrofurantoin $(300 \mu \mathrm{g})$. E. coli (American Type Culture Collection (ATCC) No. 25922) was used as the reference strain for the antibiotic susceptibility tests.

\section{Extended spectrum $\beta$-lactamase detection}

Using $\beta$-lactam and $\beta$-lactamase-inhibitor disks is a widely accepted method of detecting extended- spectrum $\beta$-lactamase (ESBL)-producing gramnegative bacilli. Isolates were screened for ESBL production using a double disk synergy test. The disks of extended-spectrum cephalosporins (cefotaxime, ceftazidime, ceftriaxone, and ceftizoxime) were placed around an amoxicillin $(20 \mu \mathrm{g})$-clavulanate $(10 \mu \mathrm{g})$ disk at a distance of $25-30 \mathrm{~mm}$ center to center. Plates were incubated at $37^{\circ} \mathrm{C}$ for $18 \mathrm{hrs}$. ESBL production was deduced when the zone of cephalosporins was expanded by clavulanate [9].

K. pneumoniae (ATCC No. 700603) and E. coli (ATCC No. 35218) were used as positive and negative ESBL controls respectively.

\section{Detection of class 1, 2 and 3 integrons by PCR- RFLP}

Genomic DNA of the isolates was extracted using a boiling method [10]. Integrons were detected by PCR with degenerate primers hep35 (5'-TGCGGG TYAARGATBTKGATTT-3') and hep36 (5'-CARC ACATGCGTRTARAT- $\left.3^{\prime}\right)$, where $\mathrm{B}=\mathrm{C}$ or $\mathrm{G}$ or $\mathrm{T}$, $\mathrm{K}=\mathrm{G}$ or $\mathrm{T}, \mathrm{R}=\mathrm{A}$ or $\mathrm{G}$ and $\mathrm{Y}=\mathrm{C}$ or $\mathrm{T}$, which hybridize to conserved regions of integron-encoded integrase genes intI1, intI2, and intI3 [11]. To amplify the integrase gene, $1 \mu \mathrm{L}$ of template DNA was added to $25 \mu \mathrm{l}$ of PCR mixture. Each reaction contained $2.5 \mu \mathrm{L}$ of $10 \times$ PCR buffer, $0.5 \mu \mathrm{L}$ of $10 \mathrm{mM}$ dNTPs, $0.7 \mu \mathrm{L}$ of each primers ( $20 \mathrm{pM}), 2 \mu \mathrm{L}$ of template DNA, and $0.2 \mu \mathrm{L}$ of $5 \mathrm{U} / \mu \mathrm{l}$ Taq DNA polymerase. Amplification conditions were as follows: early denaturation at $95^{\circ} \mathrm{C}$ for 3 min followed by 35 cycles of $94^{\circ} \mathrm{C}$ for $1 \mathrm{~min}, 52^{\circ} \mathrm{C}$ for $1 \mathrm{~min}$, and $72^{\circ} \mathrm{C}$ for $90 \mathrm{~s}$, with a final elongation step of $10 \mathrm{~min}$ at $72^{\circ} \mathrm{C}$. The length of the expected amplified fragment was about $491 \mathrm{bp}$. Clinical isolates of E. coli harboring integron class 1 and 2 genes (kindly provided from Dr. Alebouyeh, Research Center for Gastroenterology and Liver Diseases, Iran) were used as positive controls. A tube including the PCR reaction mix with no DNA template was used as negative control for all PCRs.

\section{Determination of integron classes}

To determine the integron classes, PCR products were digested with RsaI and Hinfl restriction enzymes (Cinagene, Iran). The products of each distinct RFLP were analyzed by electrophoresis in $1.3 \%$ agarose gel [5].

\section{Statistical analysis}

Chi-square and Fisher exact tests were used to 
calculate the association between antibiotic resistance and presence of integron. $P<0.05$ was considered significant.

\section{Results}

This study was performed on 111 anonymized uropathogenic $E$. coli strain isolates from urine samples of hospitalized patients and from private clinical laboratories of Alborz province, Karaj city. From 111 clinical E. coli strains, 77 (70\%) were isolated from female and 34 (30\%) from male patients. Isolates were identified as $E$. coli based on standard biochemical tests. All isolates were subjected to an antibiotic susceptibility test using the Kirby-Bauer disk diffusion method. Resistance to amoxicillin was observed in $79 \%$ of isolates, to tetracycline in $64 \%$, co-trimoxazole in $61 \%$, cephalexin in $59 \%$, nalidixic acid in $60 \%$, cephalothin in $49 \%$, ceftriaxone in $41 \%$, cefotaxime in $41 \%$, ciprofloxacin in $33 \%$, norfloxacin in $32 \%$, ofloxacin in $31 \%$, levofloxacin in $31 \%$, ceftazidime in $30 \%$, imipenem in $26 \%$, ceftizoxime in $24 \%$, gentamycin in $23 \%$, chloramphenicol in $17 \%$, amikacin in 14\%, and nitrofurantoin in 7\% (Table 1). Eighty-eight isolates of the 111 were resistant to more than 3 unrelated antibiotics. Frequencies of MDR to 4 , 5 , and 6 or more antibiotics were $75 \%, 72 \%$, and $59 \%$ respectively. By amplification of the integrase gene, it was found that 26 multidrug resistant isolates (30\%) harbor antibiotic resistance integrons. By PCRRFLP, class 1 and 2 integrons were found in 25 isolates and 1 isolate respectively (Figure 1). No class 3 integron was observed among our isolates and 62 MDR isolates did not harbor any integrons.

ESBL screening of strains by double disk diffusion showed that of the $111 \mathrm{E}$. coli isolates, 45 (40\%) were ESBL positive and $22 \%$ of the ESBL-positive isolates carried class 1 integrons. The frequency of MDR in ESBL positive isolates was $93 \%$.

Table 1. Association between antibiotic resistance and presence of integrons in E. coli isolates

\begin{tabular}{|c|c|c|c|c|}
\hline Antibiotic & $\begin{array}{l}\text { Resistant int- } \\
\text { positive* } \\
\text { (Number of } \\
\text { isolates) }\end{array}$ & $\begin{array}{l}\text { Resistant int- } \\
\text { negative }^{* *} \\
\text { (Number of } \\
\text { isolates) }\end{array}$ & $\begin{array}{c}\text { Total number of } \\
\text { isolates }\end{array}$ & $\begin{array}{l}\text { Association with } \\
\text { integron }\end{array}$ \\
\hline Nitrofurantoin & 1 & 9 & 10 & $<0.12$ \\
\hline Levofloxacin & 10 & 24 & 34 & $<0.59$ \\
\hline Amikacin & 3 & 12 & 15 & $<0.22$ \\
\hline Chloramphenicol & 4 & 15 & 19 & $<0.87$ \\
\hline Gentamycin & 6 & 20 & 26 & $<0.72$ \\
\hline Nalidixic acid & 15 & 52 & 67 & $<0.44$ \\
\hline Ciprofloxacin & 10 & 27 & 37 & $<0.23$ \\
\hline Norfloxacin & 9 & 26 & 35 & $<0.23$ \\
\hline Ofloxacin & 9 & 25 & 34 & $<0.32$ \\
\hline Tetracycline & 15 & 56 & 71 & $<0.35$ \\
\hline Amoxicillin & 20 & 68 & 88 & $<0.97$ \\
\hline Co-trimoxazole & 19 & 49 & 68 & $<0.048$ \\
\hline Imipenem & 8 & 21 & 29 & $<0.93$ \\
\hline Cephalexin & 16 & 49 & 65 & $<0.37$ \\
\hline Ceftriaxone & 11 & 34 & 45 & $<0.76$ \\
\hline Cefotaxime & 11 & 35 & 46 & $<0.77$ \\
\hline Cephalothin & 12 & 42 & 54 & $<0.74$ \\
\hline Ceftazidime & 6 & 27 & 33 & $<0.34$ \\
\hline Ceftizoxime & 5 & 22 & 27 & $<0.74$ \\
\hline
\end{tabular}

${ }^{*}$ int-positive = Integron positive, ${ }^{* *}$ int-negative = Integron negative 


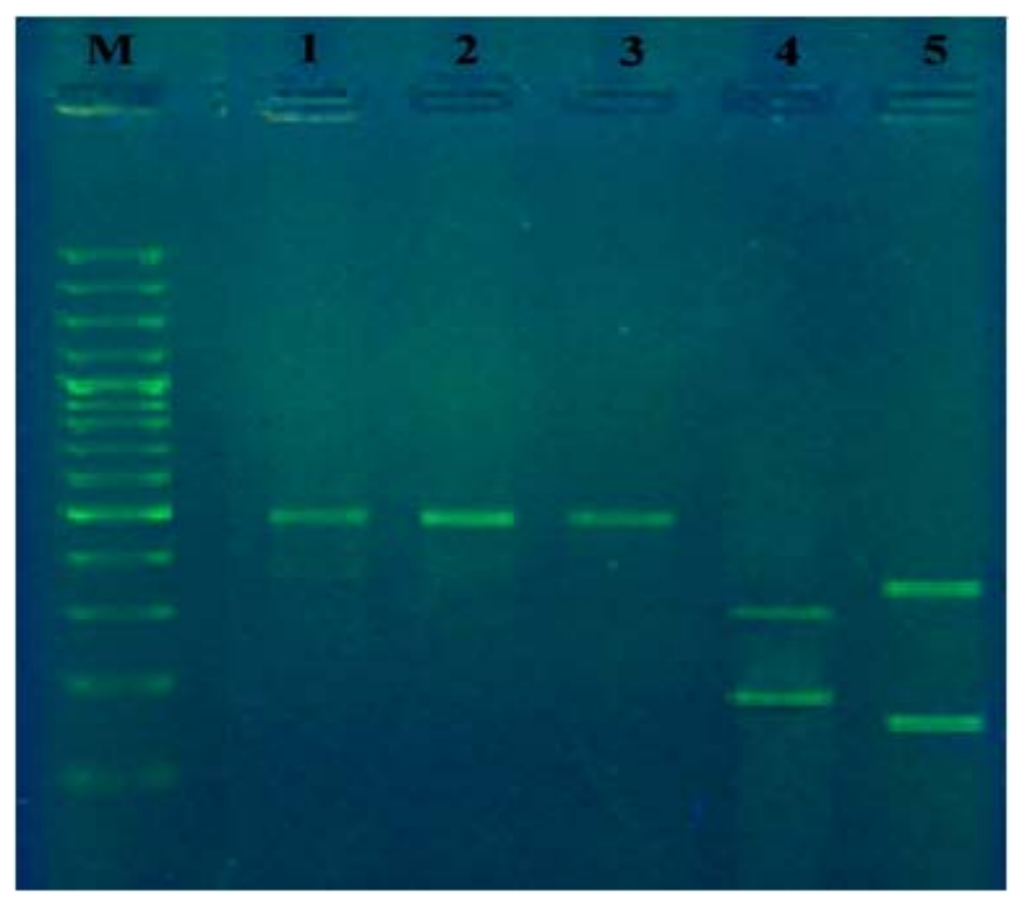

Figure 1. PCR analysis and restriction fragment length polymorphism analysis of PCR products of E. coli antibiotic resistance integrons. M: 100 bp ladder, Lane 1: positive control (491 bp), Lane 2: Class 1 integron (PCR product treated by HinfI, a 491 bp fragment), Lane 3: Class 1 integron (PCR product treated by RsaI, a 491 bp fragment), Lane 4: Class 2 integron (PCR product treated by HinfI, 300 and 191 bp fragments), Lane 5: Class 2 integron (PCR product treated by RsaI, 334 and 157 bp fragments).

\section{Discussion}

Isolates in this study were highly resistant to amoxicillin (79\%) followed by tetracycline (64\%) and co-trimoxazole (61\%). Resistance to other antimicrobial agents were as follows: nitrofurantoin (7\%) and amikacin (14\%). These finding are comparable to those of Mansouri et al. who have reported high resistance of enteric bacteria to trimethoprim/sulfamethoxazole, amoxicillin, and tetracycline and higher sensitivity to imipenem and ceftizoxime in Kerman city [12]. In 2008, Japoni et al. reported high resistance of clinical E. coli isolates in southern Iran to amoxicillin, tetracycline, and cotrimoxazole. Amikacin and imipenem have been demonstrated as the most effective drugs [1]. Extreme sensitivity to imipenem (100\%) and amikacin (99.7\%) has been reported by Oteo et al. [13]. These findings suggest that antibiotics like ampicillin, tetracycline and co-trimoxazole should be prescribed cautiously. Currently, in most of clinics in our city, ciprofloxacin is the first antibiotic that is prescribed to treat urinary tract infections (UTIs). A survey in the United States found that ciprofloxacin was the only agent studied for which the resistance of clinical $E$. coli isolates has been steadily increasing from 1995 (0.7\%) to 2001 (2.5\%). Ciprofloxacin resistance in Germany was $15.2 \%$, and in The Netherlands was $6.8 \%$, while in Portugal it was $25.8 \%$, and Italy was $24.3 \%$ [13]. In our study, the resistance to ciprofloxacin was 33\%, which is considerably higher than in all of the previous reports. This may be in part because of excessive and unregulated use of this antibiotic. In all reports noted above, imipenem has appeared to be an efficient drug, but in our study resistance to imipenem (26\%) was relatively high. It seems that antibiotics like ciprofloxacin and imipenem should be prescribed in the light of antibiograms and maybe the strategy for treatment of patients in our region with E. coli infections needs to be revised.

The major mechanism of resistance to $\beta$-lactams, particularly in gram-negative bacteria, is the production of ESBLs [14]. These enzymes are encoded on chromosomes or plasmids, and are associated with mobile genetic elements such as transposons or integrons, carrying genes that encode resistance to other antimicrobial agents. We found that our ESBL-positive isolates show higher rates of resistance to $\beta$-lactam antibiotics and $93 \%$ of them 
are MDR, which indicates that the incidence of MDR and ESBL producing enteropathogenic E. coli is high in Karaj and is cause for concern. Moreover, 22\% of the ESBL-positive and 24\% of non-ESBL isolates in this study carried class 1 integrons. These findings are comparable to those of Machado et al. [15] who have studied integron content of ESBL producing $E$. coli strains over 12 years in a single hospital in Madrid, and reported that class 1 integron occurrence was similar in ESBL-positive (47\%) and ESBL-negative (40\%) groups.

The results of this study indicate that MDR is a serious therapeutic concern. Multidrug resistance in the United States was 7.1\% in 2000 [16] and in Spain it was $17.1 \%$ and increased by $50 \%$ between 2001 and 2003 [13]. The rate of MDR in the study of Mansouri et al. for enteric bacteria in the pediatric wards of regional hospitals was $23.4 \%$ (16). Japoni et al. have reported that $82.5 \%$ of their $E$. coli isolates showed a MDR phenotype [1]. Capture of larger cassettes, with 7 to17 resistance determinates, by our integron-positive multidrug resistant isolates and widespread distribution of MDR phenotype (79\%) in our study suggest that integrons in our isolates are evolving.

Integrons play an important role in the antibiotic resistance of clinical $E$. coli strains because they are able to capture, integrate, and express gene cassettes encoding antibiotic resistance. It is well known that integrons carry and transfer MDR genes in bacteria. The prevalence of integrons ranging from 22\% to 59\% has been reported in clinical $E$. coli [1]. In our present study, we found that 26 multidrug resistant isolates (30\%) harbor antibiotic resistance integrons. The prevalence of integrons in our study was lower than that reported by Japoni et al. [1] and was similar to that in study performed by Ahangarzadeh et al. [5] who observed 27.1\% of MDR isolates were positive for integron(s). The relatively low rate of class 1 integrons among multidrug resistant $E$. coli isolates suggests that the antibiotic resistance genes in these strains were more likely to be carried on transferable elements lacking integrons. We only found a significant correlation between resistance to co-trimoxazole and integrons, but not between resistance to all of the other antibiotics tested (Table 1). However, mobilization of antibiotic resistance determinants by plasmids or transposons would be alternative approaches [1]. Findings of this study suggest that nitrofurantoin and amikacin are the most effective drugs in vitro, but clinical adequacy of monotherapy or combined administration of these antibiotics should be appraised. As regional variation in resistance patterns is usual, local surveillance of antimicrobial resistance is recommended.

\section{Acknowledgments}

This work was supported by a fund from the Islamic Azad University, Karaj Branch (No.1/192341). The authors have no conflict of interest to report.

\section{References}

1. Japoni A, Gudarzi M, Farshad SH, Basiri E, Ziyaeyan M, Alborzi A, et al. Assay for integrons and pattern of antibiotic resistance in clinical Escherichia coli strains by PCR-RFLP in southern Iran. Jpn J Infect Dis. 2008; 61:85-8.

2. Ploy MC, Lambert T, Couty JP, Denis F. Integrons: an antibiotic resistance gene capture and expression system. Clin Chem Lab Med. 2000; 38:483-7.

3. White PA, Christopher JM, William DR. Integrons and gene cassettes in the Enterobacteriaceae. Antimicrob Agents Chemother. 2001; 45:2658-61.

4. Peymani A, Farajnia S, Nahaei MR, Sohrabi N, Abbasi L, Ansarin KH, et al. Prevalence of class 1 integron among multidrug-resistant Acinetobacter baumannii in Tabriz, northwest of Iran. Pol J Microbiol. 2012; 61:57-60.

5. Ahangarzadeh Rezaee M, Sheikhalizadeh V, Hasani A. Detection of integrons among multi-drug resistant (MDR) Escherichia coli strains isolated from clinical specimens in northern west of Iran. Braz J Microbiol. 2011; 42:1308-13.

6. Rao AN, Barlow M, Clark LA, Boring JR, Tenover FC, McGowan JE Jr. Class 1 Integrons in resistant Escherichia coli and Klebsiella spp., US Hospitals. Emerg Infect Dis. 2006; 12:1011-4.

7. Schlager TA, Hendley JO, Bell AL. Clonal diversity of Escherichia coli colonizing stools and urinary tracts of young girls. Infect Immun. 2002; 70:1225-9.

8. Cockerill FR. Performance standards for antimicrobial susceptibility testing: twenty-first informational supplement: Clinical and Laboratory Standards Institute (CLSI); 2011.

9. Jarlier V, Nicolas MH, Fournier G, Philippon A. Extended broad-spectrum $\beta$-lactamases conferring transferable resistance to newer $\beta$-lactam agents in Enterobacteriaceae: hospital prevalence and susceptibility pattern. Rev Infect Dis. 1988; 10:867-78.

10. Queipo-Ortuno MI, Colmenero JD, Macias M, Bravo 
MJ, Morata P. Preparation of bacterial DNA template by boiling and effect of immunoglobulin $G$ as an inhibitor in real-time PCR for serum samples from patients with brucellosis. Clin Vaccine Immunol. 2008; 15:293-6.

11. White PA, McIver CJ, Deng YM, Rawlinson WD. Characterisation of two new gene cassettes, aadA5 and dfrA17. FEMS Microbiol Lett. 2000; 182:265-9.

12. Mansouri M, Abbasi S. Prevalence of multiple drug resistance in clinical isolates of extended spectrum beta-lactamase producing Enterobacteriaceae in southeast Iran. Iran J Med Sci. 2010; 35:101-8.

13. Oteo J, Lazaro E, de Abajo FJ, Baquero F, Campos J. Antimicrobial-resistant invasive Escherichia coli,
Spain. Emerg Infect Dis. 2005; 11: 546-53.

14. Poole K. Resistance to $\beta$-lactam antibiotics. Cell Mol Life Sci. 2004; 61:2200-23.

15. Machado E, Canton R, Baquero F, Galan JK, Rollan A, Peixe L, et al. Integron content of extended-spectrum$\beta$-lactamase-producing Escherichia coli strains over 12 years in a single hospital in Madrid, Spain. Antimicrob Agents Chemother. 2005; 49:1823-9.

16. Sahm DF, Thornsberry C, Mayfield DC, Jones ME, Karlowsky JA. Multidrug-resistant urinary tract isolates of Escherichia coli: prevalence and patient demographics in the United States. Antimicrob Agents Chemother. 2001; 45:1402-6. 